\title{
RESERVA MINERAL DE K POR DIFERENTES MÉTODOS EM ARGISSOLOS SUBTROPICAIS
}

\author{
Estefane Chaves ${ }^{(1)}$, Fabrício de Araújo Pedron ${ }^{(2) *}$, Vander Freitas de Melo ${ }^{(3)}$ e Ricardo Simão \\ Diniz Dalmolin ${ }^{(2)}$ \\ (1) Universidade Federal do Rio Grande do Sul, Departamento de Solos, Programa de Pós-graduação em Ciência do Solo, Porto Alegre, \\ Rio Grande do Sul, Brasil. \\ (2) Universidade Federal de Santa Maria, Departamento de Solos, Santa Maria, Rio Grande do Sul, Brasil. \\ (3) Universidade Federal do Paraná, Departamento de Solos e Engenharia Agrícola, Curitiba, Paraná, Brasil. \\ * Autor correspondente. \\ E-mail: fapedron@ufsm.br
}

\section{RESUMO}

A integração de métodos químicos de extração e a difração de raios-X podem ampliar o entendimento das formas de reserva de $\mathrm{K}^{+}$nas frações do solo e o seu potencial de liberação para as plantas. Os objetivos deste estudo foram empregar os métodos de extração química para estimar a reserva mineral de $\mathrm{K}^{+}$das frações areia, silte e argila de solos subtropicais, associar os mecanismos de extração com as formas liberadas do nutriente e acompanhar a dinâmica dessa liberação em estudo de cinética. As frações areia, silte e argila dos horizontes A e Bt de três Argissolos subtropicais foram submetidas à extração de formas não trocáveis e estruturais de $\mathrm{K}^{+}$pelos métodos: ácido oxálico $0,01 \mathrm{~mol} \mathrm{~L}^{-1}$ (cinética de liberação até o tempo acumulado de $2.889 \mathrm{~h}$ ); $\mathrm{HNO}_{3} 1 \mathrm{~mol} \mathrm{~L}^{-1}$ fervente; $\mathrm{NaHSO}_{4}$ na forma de cristais; e $\mathrm{HNO}_{3} / \mathrm{HF} / \mathrm{H}_{2} \mathrm{SO}_{4}$ concentrados (teores totais). A fração argila também foi submetida a tratamento com $\mathrm{NaOH}$ $5 \mathrm{~mol} \mathrm{~L}^{-1}$. As esmectitas dioctaedrais na fração argila foram consideradas importantes na dinâmica de liberação de formas de reserva de $\mathrm{K}^{+}$. A maior e menor liberação de formas não trocáveis e estruturais de $\mathrm{K}^{+}$foram pela extração com $\mathrm{NaHSO}_{4}$ e pelo ataque ácido com $\mathrm{HNO}_{3}$, respectivamente. Com os dados da cinética de liberação de $\mathrm{K}^{+}$é possível concluir que as plantas cultivadas, nos Argissolos estudados, no longo dos anos nos solos estariam bem nutridas a partir de formas não trocáveis e estruturais de $\mathrm{K}^{+}$.

Palavras-chave: K não trocável, mineralogia do solo, esmectita, ilita, ácido oxálico. 


\title{
ABSTRACT: MINERAL RESERVES OF K DETERMINED BY DIFFERENT METHODS IN SUBTROPICAL ARGISSOLOS SOILS
}

\begin{abstract}
Integration of chemical extraction methods and $X$-ray diffraction can broaden understanding of $K^{+}$forms and reserves in soil fractions, and their potential release to plants. The aim of this study was to use chemical extraction methods to estimate mineral reserves of $K^{+}$in sand, silt, and clay from subtropical soils; to associate extraction mechanisms with the forms of $K^{+}$released; and to monitor the dynamic of $K^{+}$release in a kinetics study. The sand, silt, and clay fractions of the A and Bt horizons from three subtropical Argissolos (Alfisols) underwent extraction of structural and non-exchangeable $K^{+}$forms by the following methods: $0.01 \mathrm{~mol} \mathrm{~L}^{-1}$ oxalic acid (release kinetics up to a cumulative time of 2,889 h); boiling $1 \mathrm{~mol} \mathrm{~L}^{-1} \mathrm{HNO}_{3}$; $\mathrm{NaHSO}_{4}$ in the form of crystals; and concentrated $\mathrm{HNO}_{3} / \mathrm{HF} / \mathrm{H}_{2} \mathrm{SO}_{4}$ (total contents). The clay fraction also underwent treatment with $5 \mathrm{~mol} \mathrm{~L}{ }^{-1} \mathrm{NaOH}$. Dioctahedral smectites in the clay fraction were considered important in the release dynamics of forms of the $K^{+}$reserve. The greatest amount of structural and non-exchangeable forms of $\mathrm{K}^{+}$released was by $\mathrm{NaHSO}_{4}$ fusion, and the smallest amount was by $\mathrm{HNO}_{3}$ dissolution. From the data on $\mathrm{K}^{+}$release kinetics, we conclude that plants grown in the Argissolos studied would be well nourished from non-exchangeable and structural forms of $K^{+}$over the years.
\end{abstract}

Keywords: non-exchangeable $K^{+}$, soil mineralogy, smectite, illite, oxalic acid.

\section{INTRODUÇÃO}

A adsorção específica de $\mathrm{K}^{+}$em minerais micáceos da fração argila pode ser importante para a reserva mineral, mesmo em solos altamente intemperizados dos trópicos úmidos (Melo et al., 2002, 2003; Martins et al., 2004a). O K ${ }^{+}$não trocável é retido nas cavidades ditrigonais entre lâminas tetraédricas adjacentes de minerais de argila $2: 1$, como vermiculita e minerais interestratificados (Martin e Sparks, 1985). O K ${ }^{+}$não trocável também pode ser encontrado em zonas de cunhas de micas parcialmente intemperizadas. $\mathrm{O}$ intemperismo das micas se inicia com a abertura das bordas das camadas $2: 1$, e as zonas em cunhas se formam no contato entre as camadas expandidas e colapsadas de espaçamentos basais de 1,4 e 1,0 $\mathrm{nm}$, respectivamente. Nessas áreas, os cátions com menor energia de hidratação, como o $\mathrm{K}^{+}$, podem perder a água de hidratação e penetrar mais profundamente nas cunhas (sítios de adsorção específica), onde os cátions com maior raio iônico hidratado e alta energia de hidratação $\left(\mathrm{Ca}^{2+} \mathrm{e} \mathrm{Mg}^{2+}\right)$ não conseguem chegar (Kirkman et al., 1994). O K ${ }^{+}$ assim retido está em equilíbrio no curto a médio prazo com o $\mathrm{K}^{+}$da solução do solo, cuja depleção, por absorção ou lixiviação, promove a liberação do $\mathrm{K}^{+}$não trocável, constituindo a parte principal da reserva mineral de $\mathrm{K}^{+}$nos solos.

O método-padrão para estimar a reserva mineral de $\mathrm{K}^{+}$que efetivamente tampona as formas disponíveis e contribui para a nutrição das plantas é o próprio cultivo de espécies agrícolas e florestais (Nachtigal e Vahl, 1991; Benipal e Pasricha, 2002; Alves et al., 2013). Após a colheita das plantas, é possível fazer o balanço de $\mathrm{K}^{+}$no sistema solo-planta para estimar a contribuição percentual das suas formas de reserva (Martins et al., 2004b). De forma simultânea, vários métodos de extração química têm sido empregados para estimar e diferenciar o nível de reserva mineral de $\mathrm{K}^{+}$de solos de várias partes do mundo. Os métodos químicos mais utilizados para estimar as reservas de $\mathrm{K}^{+}$em solos e em suas frações são extração com $\mathrm{HNO}_{3}$ fervente $1 \mathrm{~mol} \mathrm{~L}^{-1}$, lavagens sucessivas com $\mathrm{HCl} 0,01 \mathrm{~mol} \mathrm{~L}^{-1}$, ácidos orgânicos de baixo peso molecular (cítrico e oxálico), tetrafenil borato de sódio (NaTPB) e resinas trocadoras de cátions (Simard et al., 1992; Melo et al., 1995; Martins et al., 2004a; Sharma e Sharma, 2011).

Outros métodos químicos de extração também apresentam potencial para estimar a reserva mineral de $\mathrm{K}^{+}$. A utilização do $\mathrm{NaHSO}_{4}$, na forma de cristais, permite a solubilização completa de minerais filossilicatados secundários 1:1 (caulinita) e 2:1 (vermiculita e esmectita) e primários 2:1 (micas) (Jackson el al., 1986; Melo et al., 2003). A extração com $\mathrm{NaOH} 5 \mathrm{~mol} \mathrm{~L}^{-1}$ a quente permite a solubilização da caulinita e das esmectitas de menor tamanho e baixo grau de cristalinidade (Melo et al., 2002, 2009).

Os métodos químicos são destrutivos; por isso, a informação produzida é estática e difícil de associar a liberação da reserva de $\mathrm{K}^{+}$com o tempo de extração. A aplicação dos conhecimentos de cinética química aos estudos de solos permite quantificar a velocidade com que o $\mathrm{K}^{+}$é liberado das diferentes frações do solo, contribuindo para melhor entendimento de sua dinâmica e dos fatores que interferem sua disponibilidade para as plantas (Sharma e Sharma, 2011; Hosseinpur e Motaghian, 2013). Nesses estudos, os métodos que simulam a absorção de $\mathrm{K}^{+}$pelas plantas devem ser preferidos. Além do efeito de acidificação, os ácidos orgânicos de baixo peso molecular apresentam alta capacidade de complexação de cátions polivalentes $\left(\mathrm{Al}^{3+}, \mathrm{Fe}^{3+}\right.$, $\left.\mathrm{Si}^{4+}\right)$, que são liberados durante o ataque ácido da 
estrutura dos minerais primários fontes de $\mathrm{K}^{+}$, o que acelera o processo de extração (Srinivasarao et al., 2006). Os ácidos cítrico e oxálico são comumente encontrados na rizosfera das espécies agrícolas e florestais (Song e Huang, 1988).

A difratometria de raios-X também é essencial para caracterizar a mineralogia das frações do solo e para inferir sobre o potencial de liberação de formas não trocáveis e estruturais de $\mathrm{K}$ para as plantas. Vários autores têm usado essa técnica de natureza física para verificar a evolução da mineralogia das frações areia, silte e argila com as extrações no longo do tempo nos estudos de cinética de liberação de K (Mengel, 2000; Melo et al., 2005; Darunsontaya et al., 2010).

Os objetivos deste estudo foram empregar os diferentes métodos de extração química para estimar a reserva mineral de $\mathrm{K}^{+}$das frações areia, silte e argila de Argissolos subtropicais, associar os mecanismos de extração com as formas liberadas do nutriente e acompanhar a dinâmica dessa liberação em estudo de cinética.

\section{MATERIAL E MÉTODOS}

Foram coletadas amostras dos horizontes A e Bt de três Argissolos dos municípios de São Sepé e São Pedro do Sul no Estado do Rio Grande do Sul (Quadro 1). A geologia nos pontos de coleta pertence às Formações Sanga do Cabral, Santa Maria e São Sepé. A Formação Sanga do Cabral é constituída por arenitos finos a muito finos de origem fluvial e composição quartzo-feldspática, com porções variáveis de silte e argila. O Membro Alemoa da Formação Santa Maria é constituído principalmente por siltitos argilosos vermelhos e rosa-avermelhados de origem lacustre, maciços ou pobremente laminados, apresentando também em sua composição concreções carbonáticas do tipo calcretes. O complexo granítico São Sepé se refere a um batólito constituído por granitos ricos em plagioclásio, ortoclásio, quartzo, biotita e hornblenda (Sartori, 2009).

As regiões de coleta apresentam clima do tipo Cfa - clima subtropical úmido, sem estiagem, segundo a classificação de Köppen (Mota, 1953). A temperatura média anual é de aproximadamente $19^{\circ} \mathrm{C}$, e o regime pluvial anual médio varia de 1.450 a $1.700 \mathrm{~mm}$, bem distribuídos nos 12 meses.

As amostras de solo foram secas ao ar e tamisadas em peneira com malha de $2 \mathrm{~mm}$ para obter a terra fina seca ao ar (TFSA). A análise granulométrica foi feita pelo método da pipeta, e os teores trocáveis, após extração com solução de $\mathrm{HCl} 0,05 \mathrm{~mol} \mathrm{~L}^{-1}$, de $\mathrm{K}$ foram determinados em fotômetro de chama (Donagemma et al., 2011). Após remoção da matéria orgânica com solução de $\mathrm{H}_{2} \mathrm{O}_{2} 30 \%$ (v/v), as amostras de TFSA foram dispersas com $\mathrm{NaOH}$ $0,1 \mathrm{~mol} \mathrm{~L}^{-1}$. A fração areia $(0,05-2 \mathrm{~mm})$ foi separada por peneiramento úmido; e a fração argila $(<2 \mu \mathrm{m})$, por centrifugação (Jackson, 1979). A fração silte (2-50 $\mu \mathrm{m})$ foi obtida após remoção total da argila por centrifugação.

O K não trocável das frações areia, silte e argila foi determinado pela extração com $\mathrm{HNO}_{3} 1 \mathrm{~mol} \mathrm{~L}^{-1}$, conforme Knudsen et al. (1986), com adaptações feitas por Melo et al. (2005). Foram pesados $1 \mathrm{~g}$ de amostra das frações em erlenmeyer de $40 \mathrm{~mL}$ e adicionados $3 \mathrm{~mL}$ de $\mathrm{HNO}_{3} 1 \mathrm{~mol} \mathrm{~L}^{-1}$. Os frascos foram distribuídos em banho de areia a $113{ }^{\circ} \mathrm{C}$, permanecendo sob fervura durante $25 \mathrm{~min}$. O extrato foi filtrado em papel de filtragem lenta, e o resíduo foi lavado com $\mathrm{HNO}_{3} 0,1 \mathrm{~mol} \mathrm{~L}^{-1}$. O volume foi aferido para $50 \mathrm{~mL}$; e o $\mathrm{K}^{+}$, determinado em fotômetro de chama.

$\mathrm{O} \mathrm{K}^{+}$associado a minerais micáceos nas frações areia, silte e argila foi determinado via dissolução com $\mathrm{NaHSO}_{4}$ na forma de cristais, conforme Jackson et al. (1986), com adaptações feitas por Melo et al. (2002). Foram pesados 0,2 g de amostra das frações em béquer de teflon de $150 \mathrm{~mL}$, onde se adicionaram $15 \mathrm{~g}$ de $\mathrm{NaHSO}_{4}$ na forma de cristais. Após homogeneização, o béquer tampado foi levado ao banho de areia. Após 40 min de reação, a fervura

Quadro 1. Classificação, localização, material de origem, horizontes, granulometria e teor de potássio trocável dos Argissolos analisados

\begin{tabular}{|c|c|c|c|c|c|c|c|c|}
\hline Símbolo & Solo $^{(1)}$ & Localização UTM 22J & Litologia $^{(2)}$ & Horizonte & Argila & Silte & Areia & K trocável \\
\hline & & & & & & $\mathrm{g} \mathrm{kg}^{-1}$ & & $\mathrm{mg} \mathrm{kg}^{-1}$ \\
\hline \multirow[t]{2}{*}{ PVd } & \multirow{2}{*}{$\begin{array}{l}\text { Argissolo Vermelho distrófico } \\
\text { típico }\end{array}$} & \multirow{2}{*}{$\begin{array}{c}\text { São Sepé } \\
0250172-6661986\end{array}$} & \multirow[t]{2}{*}{ Granito } & $\mathrm{A}$ & 436 & 42 & 521 & 44,4 \\
\hline & & & & $\mathrm{Bt}$ & 655 & 12 & 332 & 16,4 \\
\hline \multirow[t]{2}{*}{ PBAC1 } & \multirow{2}{*}{$\begin{array}{l}\text { Argissolo Bruno-Acinzentado } \\
\text { alítico típico }\end{array}$} & \multirow{2}{*}{$\begin{array}{l}\text { São Pedro do Sul } \\
\text { 0774281-6717507 }\end{array}$} & \multirow[t]{2}{*}{ Siltito } & $\mathrm{A}$ & 244 & 311 & 445 & 165,4 \\
\hline & & & & $\mathrm{Bt}$ & 336 & 276 & 388 & 102,6 \\
\hline \multirow[t]{2}{*}{ PBAC2 } & \multirow{2}{*}{$\begin{array}{c}\text { Argissolo Bruno-Acinzentado } \\
\text { alítico típico }\end{array}$} & \multirow{2}{*}{$\begin{array}{c}\text { São Pedro do Sul } \\
0757226-6717929\end{array}$} & \multirow[t]{2}{*}{ Arenito } & $\mathrm{A}$ & 166 & 436 & 399 & 38,1 \\
\hline & & & & $\mathrm{Bt}$ & 325 & 566 & 109 & 19,5 \\
\hline
\end{tabular}

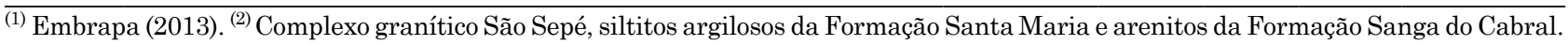


tornou-se mais branda e, por causa dos aumentos progressivos, a temperatura alcançou $250{ }^{\circ} \mathrm{C}$. Deixaram-se os béqueres no banho de areia por mais $2 \mathrm{~h}$ à temperatura de $270{ }^{\circ} \mathrm{C}$. Após o tempo da reação (160 min), a mistura transformou-se em um resíduo seco, que foi dissolvido por meio de três lavagens sucessivas com $\mathrm{HCl} 3 \mathrm{~mol} \mathrm{~L}^{-1}$ em banho de areia a $80^{\circ} \mathrm{C}$. Após centrifugação, os extratos foram combinados em balão volumétrico de $100 \mathrm{~mL}$.

$\mathrm{O} \mathrm{K}^{+}$associado à caulinita e vermiculita/esmectita na fração argila foi determinado via dissolução com $\mathrm{NaOH} 5 \mathrm{~mol} \mathrm{~L}^{-1}$ a quente, conforme Norrish e Taylor (1961) e Singh e Gilkes (1991). O K ${ }^{+}$total nas frações areia, silte e argila foi determinado via dissolução com $\mathrm{HNO}_{3}$ - $\mathrm{HF}-\mathrm{H}_{2} \mathrm{SO}_{4}$ concentrados (Pratt, 1965).

A cinética de liberação de $\mathrm{K}^{+}$das frações areia, silte e argila foi realizada conforme procedimento de Castilhos e Meurer (2001), com adaptações. Em tubos de centrífuga de $30 \mathrm{~mL}$, foram adicionados $2 \mathrm{~g}$ de amostra e $20 \mathrm{~mL}$ de ácido oxálico $0,01 \mathrm{~mol} \mathrm{~L}^{-1}$. $\mathrm{Na}$ primeira extração, o tempo de contato foi de $2 \mathrm{~h}$, sendo $1 \mathrm{~h}$ em agitador mecânico horizontal e $1 \mathrm{~h}$ em repouso. A suspensão foi centrifugada a $3.000 \mathrm{rpm}$, e $\mathrm{o} \mathrm{K}^{+}$no sobrenadante foi determinado por fotometria de chama. Na amostra remanescente no tubo de centrífuga, adicionaram-se mais $20 \mathrm{~mL}$ da mesma solução extratora, repetindo esse procedimento até o total de 15 extrações. A cada reposição da solução extratora, os tubos foram agitados por $1 \mathrm{~h}$ em agitador. $\mathrm{O}$ tempo total de contato de cada extração (agitação mais repouso) foi de $2 ; 5 ; 34 ; 55 ; 88 ; 118$; $163 ; 166 ; 188 ; 190 ; 190 ; 190 ; 305 ; 456$; e 739 h, com tempo total acumulado de $2.889 \mathrm{~h}$.

Equações parabólicas de difusão foram ajustadas aos dados (Melo et al., 2005; Jalali e Zarabi, 2006; Silva et al., 2008; Sharma e Sharma, 2011). Esses autores usaram os teores acumulados de metal no tempo $\mathrm{t}(\mathrm{Mt})$ relativo ao teor total acumulado liberado ao final do experimento de cinética $\left(\mathrm{Mt}=\mathrm{a}+\mathrm{kt}^{1 / 2}\right)$, sendo $\mathrm{t}$ os tempos acumulados $\mathrm{e}$ Mt os teores acumulados de $\left(\mathrm{mg} \mathrm{kg}^{-1}\right)$ liberados até o tempo t (h). Os valores do coeficiente angular (k) expressam a taxa ou velocidade de liberação de $\mathrm{K}^{+}$ em $\mathrm{mg}$ de $\mathrm{K}^{+}$por $\mathrm{kg}$ de argila por $\mathrm{h}^{1 / 2}$. O estudo de cinética foi feito em triplicata com coeficiente de variação $(\mathrm{CV})$ inferior a $5 \%$ para todas as amostras; por isso, apenas os valores médios foram usados para ajustar as equações parabólicas de difusão.

$\mathrm{Na}$ difratometria de raios-X (DRX), as amostras de areia e silte foram moídas e analisadas em lâminas em pó. As amostras de argila foram analisadas em lâminas orientadas pela técnica do esfregaço. Foi utilizado um difratômetro com goniômetro vertical, com intervalo de leitura de 3 a $45^{\circ} 2 \theta$ e velocidade angular de $0,5^{\circ} 2 \theta \mathrm{min}^{-1}$, equipado com anodo de $\mathrm{Cu}$ e filtro de Ni.

Para facilitar a expressão dos reflexos de minerais 2:1 secundários por DRX, foi usada amostra de argila previamente tratada com ditionito-citrato-bicarbonato para remoção dos óxidos de Fe pedogenéticos (Mehra e Jackson, 1960). Foram empregados os seguintes tratamentos na argila desferrificada (Whittig e Allardice, 1986): saturação com $\mathrm{Mg}$, saturação com $\mathrm{Mg}$ e solvatação com glicerol, saturação com $\mathrm{K}$ e secagem ao ar e saturação com $\mathrm{K}$ e aquecimentos a 110 e $550{ }^{\circ} \mathrm{C}$. Após a confirmação da ocorrência de esmectita, foi realizado o teste de Greene-Kelly (Greene-Kelly, 1953, modificado por Lim e Jackson, 1986), em que as amostras de argila foram saturadas com solução de LiCl $1 \mathrm{~mol} \mathrm{~L}^{-1}$. Para verificar o efeito do contato das amostras com ácido oxálico $0,01 \mathrm{~mol} \mathrm{~L}^{-1}$ sobre os minerais, a fração argila foi analisada por DRX antes e após o estudo de cinética.

Realizaram-se análises de correlações simples (Pearson) entre os teores acumulados de $\mathrm{K}^{+}$e outros parâmetros no estudo de cinética e os teores totais e extraídos com $\mathrm{HNO}_{3} 1 \mathrm{~mol} \mathrm{~L}^{-1}, \mathrm{NaOH} 5 \mathrm{~mol} \mathrm{~L}^{-1} \mathrm{e}$ $\mathrm{NaHSO}_{4}$ (cristais).

\section{RESULTADOS E DISCUSSÃO}

\section{Formas de $\mathrm{K}^{+}$nas frações areia, silte e argila}

A liberação de $\mathrm{K}^{+}$das frações do solo por diferentes métodos de extração (Quadro 2) pode ser atribuída apenas a fontes não trocáveis e estruturais do nutriente (formas de reserva), uma vez que para dispersão das amostras de solo foram utilizados tratamentos com água oxigenada $30 \%(\mathrm{v} / \mathrm{v})$ e $\mathrm{NaOH}$ $0,1 \mathrm{~mol} \mathrm{~L}^{-1}$. A distinção entre essas duas formas de reserva é que o $\mathrm{K}^{+}$estrutural está ligado dentro da estrutura do mineral (Martin e Sparks, 1985) ou, ainda, a liberação de $\mathrm{K}^{+}$não trocável é um processo reversível, enquanto a liberação do $\mathrm{K}^{+}$estrutural é irreversível, envolvendo reações de dissolução (Kirkman et al., 1994).

De maneira geral, os teores totais de $\mathrm{K}^{+}$foram altos e compatíveis com solos menos intemperizados (Argissolos), com presença de minerais primários fontes de $\mathrm{K}^{+}$e com predominância de minerais secundários 2:1 (Mengel, 2000). Na fração argila, foi evidente o predomínio de esmectita nos PBAC e a ocorrência de minerais micáceos e feldspato-K em todas as amostras (Figura 1). Os PBAC, originados de rochas sedimentares, apresentaram maiores reservas de $\mathrm{K}^{+}$que o PVd formado do intemperismo de granito. $\mathrm{O}$ arenito do PBAC2 evidencia composição quartzo-feldspática; e os siltitos, concreções carbonáticas e minerais micáceos (Sartori, 2009).

A ocorrência de feldspato- $K$ nas frações mais grosseiras dos horizontes $\mathrm{A}$ e $\mathrm{Bt}$ do PBAC2 determinou os maiores teores de $\mathrm{K}$ total na areia e silte em relação às mesmas frações das demais 
Quadro 2. Teores de $\mathrm{K}^{+}$total e extraídos com $\mathrm{HNO}_{3}$, ácido oxálico, $\mathrm{NaHSO}_{4}$ na fração areia, silte e argila e com $\mathrm{NaOH}$ na fração argila dos horizontes A e Bt dos Argissolos analisados

\begin{tabular}{|c|c|c|c|c|c|c|}
\hline Solo $^{(1)}$ & Horizonte & $\mathrm{HNO}_{3}$ & Ácido Oxálico (2) & $\mathrm{NaOH}^{(3)}$ & $\mathrm{NaHSO}_{4}$ & Total \\
\hline & & \multicolumn{5}{|c|}{$\mathrm{mg} \mathrm{kg}^{-1}$} \\
\hline & & & & Areia & & \\
\hline \multirow[t]{2}{*}{$\mathrm{PVd}$} & $\mathrm{A}$ & 14,8 & 37,6 & - & 49,0 & 511,3 \\
\hline & $\mathrm{Bt}$ & 8,4 & 21,3 & - & 93,5 & 349,0 \\
\hline \multirow[t]{2}{*}{ PBAC1 } & $\mathrm{A}$ & 27,3 & 62,7 & - & 160,9 & $1.447,9$ \\
\hline & $\mathrm{Bt}$ & 23,1 & 88,0 & - & 155,7 & 931,4 \\
\hline \multirow[t]{3}{*}{ PBAC2 } & $\mathrm{A}$ & 55,3 & 214,4 & - & 421,5 & $8.530,9$ \\
\hline & $\mathrm{Bt}$ & 147,8 & 485,4 & - & $1.445,0$ & $8.003,9$ \\
\hline & & & & Silte & & \\
\hline \multirow[t]{2}{*}{ PVd } & $\mathrm{A}$ & 34,6 & 153,1 & - & 320,0 & $2.660,6$ \\
\hline & $\mathrm{Bt}$ & 27,3 & 67,9 & - & 383,8 & $2.150,4$ \\
\hline \multirow[t]{2}{*}{ PBAC1 } & $\mathrm{A}$ & 89,7 & 333,9 & - & $1.149,2$ & $7.429,1$ \\
\hline & $\mathrm{Bt}$ & 95,2 & 294,9 & - & 895,5 & $6.929,8$ \\
\hline \multirow[t]{3}{*}{ PBAC2 } & $\mathrm{A}$ & 193,5 & 406,6 & - & $1.318,6$ & $8.406,6$ \\
\hline & $\mathrm{Bt}$ & 681,0 & $1.443,0$ & - & $3.520,0$ & $8.164,5$ \\
\hline & & & & Argila & & \\
\hline \multirow[t]{2}{*}{ PVd } & $\mathrm{A}$ & 894,7 & 875,0 & $1.602,9$ & $3.156,5$ & $4.449,5$ \\
\hline & $\mathrm{Bt}$ & 384,5 & 383,2 & $1.911,9$ & $2.450,0$ & $4.353,4$ \\
\hline \multirow[t]{2}{*}{ PBAC1 } & $\mathrm{A}$ & 907,0 & $2.903,8$ & $2.274,2$ & $5.524,5$ & $8.823,4$ \\
\hline & $\mathrm{Bt}$ & 999,3 & $3.986,6$ & $3.772,5$ & $6.898,0$ & $8.353,0$ \\
\hline \multirow[t]{2}{*}{ PBAC2 } & $\mathrm{A}$ & 941,6 & $2.011,3$ & $1.878,1$ & $4.048,7$ & $4.794,0$ \\
\hline & $\mathrm{Bt}$ & 920,4 & $2.186,0$ & $1.868,5$ & $3.783,2$ & $6.603,0$ \\
\hline
\end{tabular}

(1) PVd: Argissolo Vermelho distrófico típico; PBAC1: Argissolo Bruno-Acinzentado alítico típico - siltito; PBAC2: Argissolo Bruno-Acinzentado alítico típico - arenito. ${ }^{(2)}$ Teor acumulado no estudo de cinética após 2.889 h de extração. ${ }^{(3)}$ Usado apenas na fração argila.

amostras (Quadro 2). Nas amostras do PVd e PBAC1, mesmo com teores também expressivos de $\mathrm{K}^{+}$total, não foram identificadas reflexões por DRX de minerais primários fontes de $\mathrm{K}^{+}$nas frações areia e silte (padrão apenas de quartzo). Entretanto, os maiores teores totais de $\mathrm{K}^{+}$da fração argila foram observados no PBAC1, indicando que o intemperismo químico nas camadas mais externas dos minerais primários fontes de $\mathrm{K}^{+}$do tamanho areia e silte nesse solo foi mais intenso em relação ao PBAC2, reduzindo o diâmetro e levando os núcleos das partículas para o tamanho argila $(<2 \mu \mathrm{m})$. Também, um fator que deve ter contribuído para esse comportamento é o menor tamanho original dos minerais primários fontes de $\mathrm{K}^{+}$do siltito argiloso (PBAC1) em relação ao arenito (PBAC2).

Entre os métodos de estimativa das formas de reserva de $\mathrm{K}^{+}$, a extração nítrica solubilizou as menores quantidades do nutriente (Quadro 2). O $\mathrm{HNO}_{3} 1 \mathrm{~mol} \mathrm{~L}^{-1}$ fervente é o método mais rápido e simples de estimar o teor de $\mathrm{K}$ não trocável do solo (Nachtigal eVahl, 1991; Melo et al., 1995; Benipal e Pasricha, 2002; Martins et al., 2004b). $\mathrm{O}$ método baseia-se na acidificação do meio e ataque parcial das estruturas, principalmente, de feldspatos e micas pelo $\mathrm{H}^{+}$(Simard et al., 1992; Benipal et al., 2006).

Alguns ácidos apresentam efeito adicional à acidificação pela complexação dos íons liberados, como o oxalato e os demais ácidos orgânicos de baixo peso molecular, complexantes de cátions na dissolução de mica e feldspato (Simard et al., 1992). Após $2.889 \mathrm{~h}$ de contato das amostras das frações areia, silte e argila com solução de ácido oxálico $0,01 \mathrm{~mol} \mathrm{~L}^{-1}$, a liberação de formas de reserva de $\mathrm{K}^{+}$foi superior em relação à extração nítrica (Quadro 2). O ácido oxálico extraiu totalmente o $\mathrm{K}^{+}$ não trocável e solubilizou uma parcela maior de $\mathrm{K}$ estrutural em relação à extração nítrica. $\mathrm{O}$ baixo peso molecular dos ácidos orgânicos com grupos $\mathrm{OH}$ e $\mathrm{COOH}$ na posição orto tendem a formar complexos organo-metálicos em solução com muitos outros íons metálicos, acelerando a decomposição dos minerais (Srinivasarao et al., 2006).

A extração com o $\mathrm{NaHSO}_{4}$ é mais agressiva, ocorrendo a liberação total do $\mathrm{K}^{+}$não trocável e a solubilização completa dos minerais secundários 

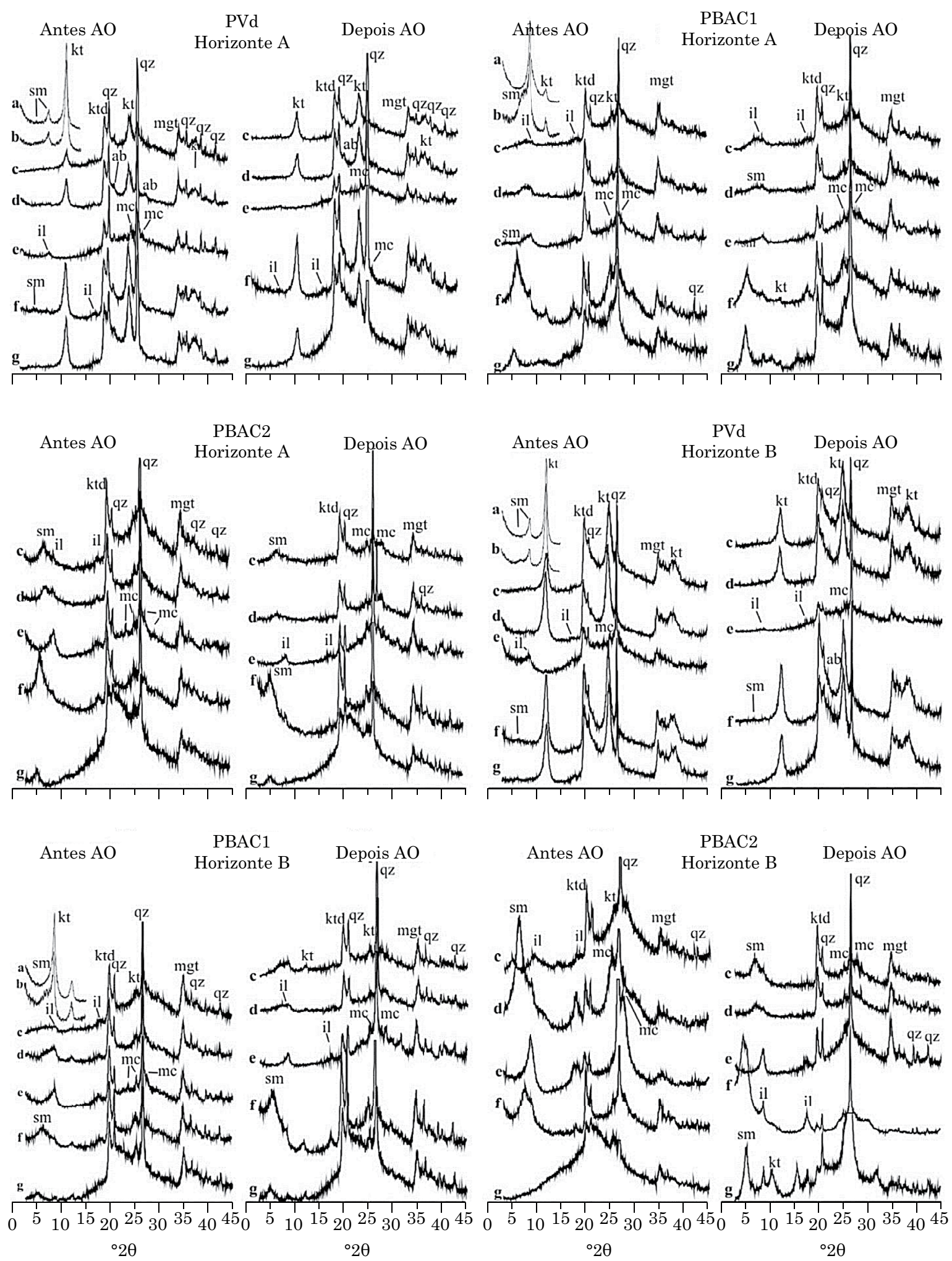

Figura 1. Difratogramas de raios-X da fração argila desferrificada dos horizontes A e Bt do Argissolo Vermelho distrófico típico (PVd), PBAC1: Argissolo Bruno-Acinzentado alítico típico - siltito (PBAC1), e Argissolo Bruno-Acinzentado alítico típico - arenito (PBAC2), antes e após a extração de $\mathrm{K}^{+}$por 2.889 h com ácido oxálico (AO). be - beidelita; no - nontronita; sm - esmectita; kt - caulinita; il - ilita; qz - quartzo; me - microclínio; ab - albita. a - amostra saturada com Li e aquecida a $250{ }^{\circ} \mathrm{C}$; b - amostra saturada com Li e glicerol e aquecida a $110^{\circ} \mathrm{C} ; \mathrm{c}$ - amostra saturada com $\mathrm{K}$ a $25^{\circ} \mathrm{C} ; \mathrm{d}$ - amostra saturada com $\mathrm{K}$ e aquecida a $110^{\circ} \mathrm{C}$; $\mathrm{e}$ - amostra saturada com $\mathrm{K}$ e aquecida a $550^{\circ} \mathrm{C}$; $\mathrm{f}$ - amostra saturada com $\mathrm{Mg}$ a $25^{\circ} \mathrm{C}$; e g - amostra saturada com Mg e glicerol a $25^{\circ} \mathrm{C}$. 
1:1 e 2:1 e das micas (Melo et al., 2002). Mesmo com maior poder de extração, o $\mathrm{NaHSO}_{4}$ não solubiliza minerais da classe dos tectossilicatos (Jackson et al., 1986), e a manutenção dos feldspatos-K foi determinante para a grande diferença entre os teores de $\mathrm{K}^{+}$desse extrator em relação aos teores totais nas frações areia e silte (Quadro 2).

$\mathrm{Na}$ fração argila, todos os métodos de extração ficaram mais próximos dos teores totais. A liberação de $\mathrm{K}^{+}$é mais rápida em partículas mais finas de minerais primários fontes do nutriente em razão da maior superfície específica e da menor distância em que os íons precisam se difundir (Tributh et al., 1987; Benipal et al., 2006).

Uma parcela expressiva do $\mathrm{K}^{+}$liberado pelo $\mathrm{NaHSO}_{4}$ na fração argila também foi solubilizada pelo $\mathrm{NaOH} 5 \mathrm{~mol} \mathrm{~L}^{-1}$ (Quadro 2). Os valores para as relações $\mathrm{K}-\mathrm{NaOH} / \mathrm{K}-\mathrm{NaHSO}_{4}$ variaram de 0,41 a 0,78 (dados não mostrados). Mesmo sendo desenvolvido originalmente para a extração exclusiva de gibbsita e minerais secundários 1:1 (caulinita) (Singh e Gilkes, 1991), o NaOH $5 \mathrm{~mol} \mathrm{~L}^{-1}$ também ataca quantidade expressiva de esmectita, principalmente aquelas de menor tamanho e cristalinidade (Melo et al., 2009). No entanto, não é esperada a solubilização de minerais 2:1 primários (micas) por essa solução básica (Melo e al., 2002), o que sugere que a fração argila dos PBAC é essencialmente esmectítica. De acordo com os tratamentos com $\mathrm{K}, \mathrm{Mg}, \mathrm{Li}$, glicerol e aquecimento, pode-se concluir que os minerais 2:1 secundários são do grupo das esmectitas, constituído principalmente por minerais dioctaedrais com carga octaedral (montmorilonita) e menor participação das espécies com carga tetraedral (beidelita/nontronita).

Em razão da semelhança de ação dos métodos (produção de $\mathrm{H}^{+}$) e do tamponamento natural das diferentes formas de $\mathrm{K}^{+}$, verificou-se estreita correlação (valor de r) entre os teores do nutriente obtidos por diferentes métodos de extração $(p<0,05)$, conforme se segue: fração areia-ácido oxálico versus $\mathrm{HNO}_{3}, \mathrm{NaHSO}_{4}$ e total = 0,99; 0,99; e 0,84 , respectivamente; $\mathrm{HNO}_{3}$ versus $\mathrm{NaHSO}_{4}$ e total $=0,99$ e 0,81 , respectivamente; fração silte-ácido oxálico versus $\mathrm{HNO}_{3}$ e $\mathrm{NaHSO}_{4}=0,99$ e 0,99, respectivamente; $\mathrm{HNO}_{3}$ versus $\mathrm{NaHSO}_{4}=0,99$; fração argila-ácido oxálico versus $\mathrm{NaHSO}_{4}$ e total $=0,98$ e 0,88 , respectivamente, e $\mathrm{NaHSO}_{4}$ versus total $=0,88$.

\section{Cinética de liberação de $\mathrm{K}^{+}$das frações areia, silte e argila}

A cinética de liberação de $\mathrm{K}^{+}$apresentou mais de uma taxa ou velocidade simultânea, ou seja, segmentos de reta com declividades diferentes (Figura 2; Quadros 3, 4 e 5). O comportamento multifásico representa a liberação de formas de reserva de $\mathrm{K}^{+}$com diferentes energias de interação com a matriz mineral (Benipal et al., 2006; Jalali e Zarabi, 2006; Ghiri et al., 2011; Hosseinpur e Motaghian, 2013).

Nas frações areia e silte, a liberação ocorreu em três fases e na argila em quatro, com diferentes taxas. $\mathrm{O}$ intervalo equivalente da primeira fase das frações areia e silte (seis primeiros tempos) foi dividido em duas fases na fração argila, sendo a primeira mais rápida até 7 h (Figura 2). Jalali e Zarabi (2006) também usaram a equação parabólica de difusão para ajustar os dados de liberação acumulada de $\mathrm{K}$ extraído com ácido oxálico $0,01 \mathrm{~mol} \mathrm{~L}^{-1} \mathrm{em}$ amostra de solo (teor de argila inferior a $431 \mathrm{~g} \mathrm{~kg}^{-1}$ ) e observaram que a primeira fase mais rápida se estendeu até $164 \mathrm{~h}$.

$\mathrm{Na}$ fração areia, com exceção da passagem da segunda para a terceira fase no horizonte Bt do PBAC2, todas as demais relações entre a declividade do segmento posterior sobre o anterior (por exemplo, relação 1 - relação coeficiente angular da $2^{\text {a }}$ fase/coeficiente angular $1^{\text {a }}$ fase) foram maiores que 1,0 (Quadro 3), em razão do aumento progressivo na velocidade de liberação de $\mathrm{K}$ com o tempo de extração (Figuras 2a e 2b). Na fração silte, na maioria das amostras, as declividades da terceira fase foram inferiores às da segunda (Quadro 4; Figuras 2c e 2d). Já na fração mais fina, todas as curvas tenderam ao platô, onde as relações entre as declividades das diferentes fases foram inferiores a 1,0 (Figuras 2e e 2f, Quadro 5).

A tendência das curvas da argila de atingirem o platô não significa que toda a reserva de $\mathrm{K}^{+}$ foi liberada pelo ácido oxálico. Após $2.889 \mathrm{~h}$ de extração, as reflexões de ilita e feldspato-K ainda são evidentes nos difratogramas de raios-X (Figura 1). Em relação aos teores totais, o teor acumulado na extração com ácido oxálico após 15 extrações na argila não ultrapassou 47,7\%. Deve ter ocorrido a liberação preferencial do $\mathrm{K}^{+}$ estrutural de posições mais externas dos cristais da ilita e do feldspato- $\mathrm{K}$ e a liberação total do $\mathrm{K}^{+}$ não trocável das zonas em cunha da ilita (tendência de estabilização na quarta fase). Bolt et al. (1963) classificaram as formas de reserva de $\mathrm{K}^{+}$nas ilitas em três categorias crescentes em termos de estabilidade: íons que ocupam as zonas de cunha (K não trocável); posição entrecamadas perto das bordas (K estrutural); e íons $\mathrm{K}^{+}$que ocupam posições entrecamadas longe de zonas de cunha ( $\mathrm{K}$ estrutural). Benipal et al. (2006), em solos da Índia, atribuíram a liberação de formas mais estáveis de $\mathrm{K}^{+}$na última fase do estudo de cinética a sítios das entrecamadas de minerais filossilicatos.

Em todas as fases, a velocidade de liberação de $\mathrm{K}^{+}$(coeficientes angulares das retas - valor $\mathrm{k}$ ) foi muito superior na fração argila em relação a areia e silte, notadamente na primeira e segunda fase (Figura 3). Na primeira fase, a taxa de liberação máxima de $\mathrm{K}^{+}$foi para o horizonte $\mathrm{A}$ do PBAC1: 
(a)

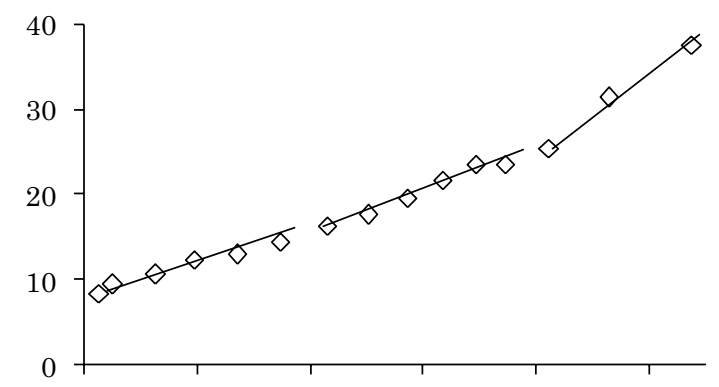

(c)

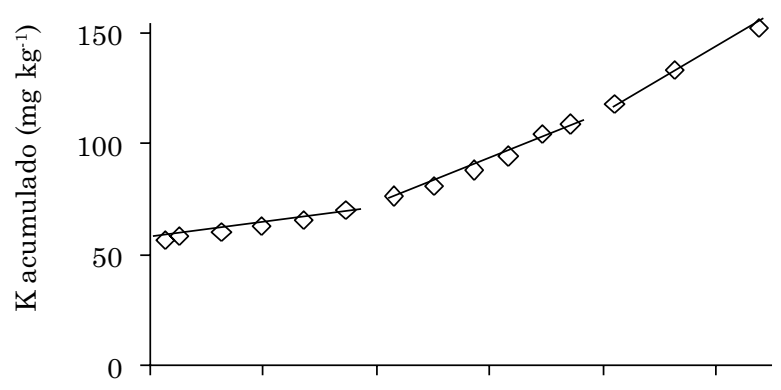

(e)

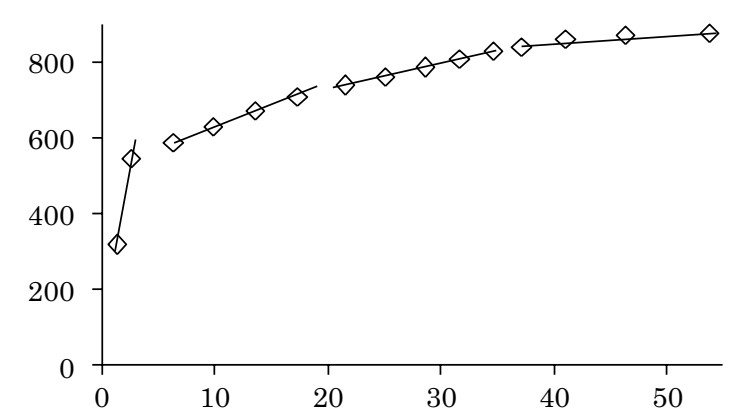

(b)

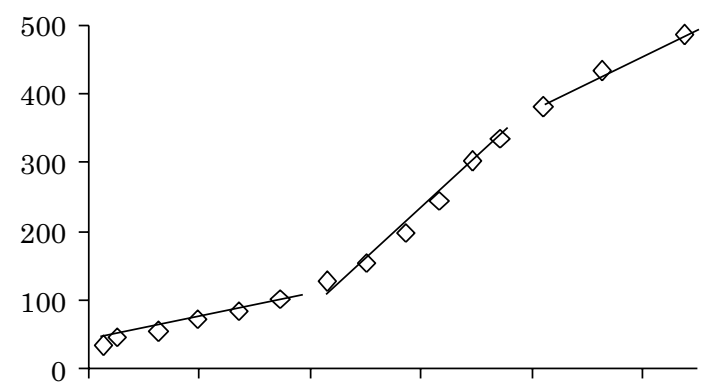

(d)

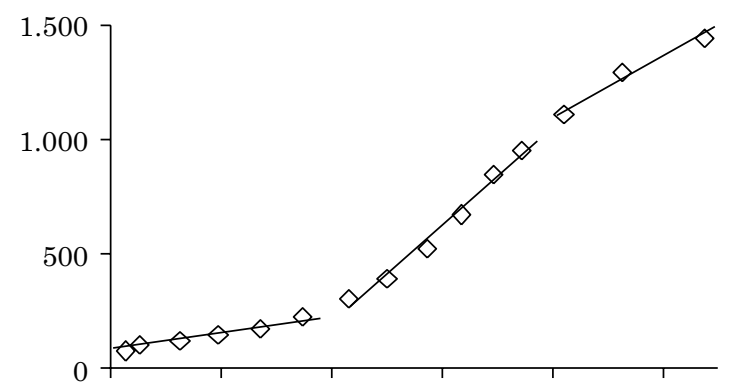

(f)

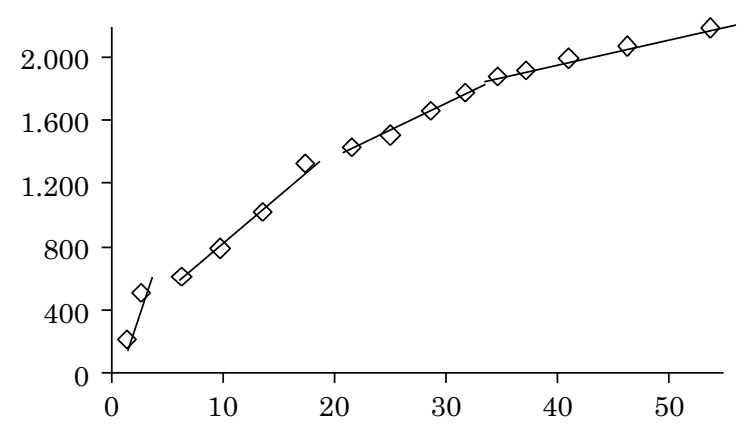

Tempo $\left(\mathrm{h}^{1 / 2}\right)$

Figura 2. Ajuste da equação parabólica de difusão $\left(\mathrm{Mt}=\mathrm{a}+\mathrm{kt}^{1 / 2}\right)$ nas frações areia [horizonte $\mathrm{A}$ do $\mathrm{PVd}(\mathrm{a})$ e Bt do PBAC2 (b)], silte [horizonte A do PVd (c) e Bt do PBAC2 (d)] e argila [horizonte A do PVd (e) e Bt do PBAC2 (f)]. Argissolo Vermelho distrófico típico (PVd), Argissolo Bruno-Acinzentado alítico típico - siltito (PBAC1), e Argissolo Bruno-Acinzentado alítico típico - arenito (PBAC2).

valor $\mathrm{k}=515,9 \mathrm{mg}$ de $\mathrm{K}^{+}$por $\mathrm{kg}$ de argila por $\mathrm{h}^{1 / 2}$. Nas frações areia e silte da mesma amostra, o valor de $\mathrm{k}$ foi apenas de 0,81 e $2,93 \mathrm{mg} \mathrm{kg}^{-1} \mathrm{~h}^{-1 / 2}$, respectivamente. Além da maior velocidade de liberação de $\mathrm{K}^{+}$, o total acumulado após $2.889 \mathrm{~h}$ de extração com ácido oxálico na fração argila variou de 383 a $3.987 \mathrm{mg} \mathrm{kg}^{-1}$. Nas frações areia e silte, as liberações máximas acumuladas foram de $485 \mathrm{e}$ $1.443 \mathrm{mg} \mathrm{kg}^{-1}$, respectivamente (Quadro 2).

Apenas na terceira fase, a velocidade de liberação de $\mathrm{K}^{+}$do silte se aproximou da taxa da argila
(Figura 3). Com a reserva mineral (Figura 1), teores acumulados com ácido oxálico (Quadro 2) e velocidades de liberação de $\mathrm{K}^{+}$(Quadro 5) da fração argila, as formas estruturais de $\mathrm{K}^{+}$das frações mais grosseiras possivelmente serão utilizadas pelas plantas em condições de campo apenas quando houver completo intemperismo químico dos minerais fontes do nutriente na fração coloidal. A única correlação significativa entre teores trocáveis de $\mathrm{K}^{+}$ dos solos (Quadro 1) e teores totais (Quadro 2) foi para a argila $(r=0,84, p<0,05)$. 
Quadro 3. Coeficientes da equação parabólica de difusão $\left(M t=a+k t^{1 / 2}\right)$ para as diferentes fases de liberação de $\mathrm{K}^{+}$das amostras de areia dos horizontes A e Bt dos Argissolos analisados

\begin{tabular}{|c|c|c|c|c|c|c|}
\hline Solo $^{(1)}$ & Horizonte & Fase $^{(2)}$ & $\begin{array}{l}\text { Coeficiente } \\
\text { angular (k) }\end{array}$ & $\mathbf{R}^{2}$ & $R 1^{(3)}$ & $\mathbf{R} 2^{(4)}$ \\
\hline & \multicolumn{6}{|c|}{$\mathrm{mg} \mathrm{kg}^{-1} \mathrm{~h}^{-1 / 2}$} \\
\hline \multirow[t]{6}{*}{ PVd } & $\mathrm{A}$ & $1^{a}(n=6)$ & 0,36 & 0,981 & 1,42 & 1,88 \\
\hline & & $2^{\mathrm{a}}(\mathrm{n}=6)$ & 0,51 & 0,975 & & \\
\hline & & $3^{\mathrm{a}}(\mathrm{n}=3)$ & 0,96 & 0,993 & & \\
\hline & $\mathrm{Bt}$ & $1^{a}(n=6)$ & 0,18 & 0,800 & 1,05 & 3,53 \\
\hline & & $2^{\mathrm{a}}(\mathrm{n}=6)$ & 0,19 & 0,971 & & \\
\hline & & $3^{a}(n=3)$ & 0,67 & 0,990 & & \\
\hline \multirow[t]{6}{*}{ PBAC1 } & A & $1^{a}(n=6)$ & 0,81 & 0,956 & 1,20 & 1,06 \\
\hline & & $2^{\mathrm{a}}(\mathrm{n}=6)$ & 0,97 & 0,985 & & \\
\hline & & $3^{a}(n=3)$ & 1,03 & 1,000 & & \\
\hline & $\mathrm{Bt}$ & $1^{a}(n=6)$ & 0,62 & 0,990 & 1,32 & 1,46 \\
\hline & & $2^{\mathrm{a}}(\mathrm{n}=6)$ & 0,83 & 0,990 & & \\
\hline & & $3^{a}(n=3)$ & 1,21 & 0,998 & & \\
\hline \multirow[t]{6}{*}{ PBAC2 } & A & $1^{a}(n=6)$ & 1,64 & 0,979 & 1,95 & 1,25 \\
\hline & & $2^{\mathrm{a}}(\mathrm{n}=6)$ & 3,17 & 0,997 & & \\
\hline & & $3^{a}(n=3)$ & 3,97 & 0,999 & & \\
\hline & $\mathrm{Bt}$ & $1^{a}(n=6)$ & 4,08 & 0,983 & 3,38 & 0,60 \\
\hline & & $2^{\mathrm{a}}(\mathrm{n}=6)$ & 13,80 & 0,983 & & \\
\hline & & $3^{\mathrm{a}}(\mathrm{n}=3)$ & 8,23 & 0,991 & & \\
\hline
\end{tabular}

(1) PVd: Argissolo Vermelho distrófico típico; PBAC1: Argissolo Bruno-Acinzentado alítico típico - siltito; PBAC2: Argissolo Bruno-Acinzentado alítico típico - arenito. ${ }^{(2)}$ As equações foram ajustadas com os valores médios de três observações para cada amostra com CV inferior a $5 \%$; n - número de amostras usadas para ajustar a equação da reta em cada fase. (3) R1: relação coeficiente angular da $2^{\mathrm{a}}$ fase/coeficiente angular $1^{\text {a }}$ fase. ${ }^{(4)} \mathrm{R} 2$ : relação coeficiente angular da $3^{\mathrm{a}}$ fase/coeficiente angular $2^{\mathrm{a}}$ fase.

Para as três frações do solo, houve correlações positivas e significativas entre os valores dos coeficientes angulares (k) (Quadros 3, 4 e 5) e diferentes métodos de extração de $\mathrm{K}^{+}$(Quadro 2) apenas para a segunda fase de liberação $(p<0,05)$, conforme se seguem: areia - valor de $\mathrm{k}$ versus acumulado ácido oxálico, $\mathrm{HNO}_{3}$ e $\mathrm{NaHSO}_{4}=0,91$; 0,95 ; e 0,93 , respectivamente; silte - valor de $\mathrm{k}$ versus acumulado ácido oxálico, $\mathrm{HNO}_{3}, \mathrm{NaHSO}_{4}$ e total $=0,77 ; 0,77 ; 0,84 ;$ e 0,88 , respectivamente; argila - valor de $\mathrm{k}$ versus acumulado ácido oxálico, $\mathrm{NaHSO}_{4}$ e total $=0,93 ; 0,88 ;$ e 0,96, respectivamente. Essas correlações indicam que a segunda fase foi mais importante para definir o comportamento das extrações totais com ácido oxálico (teor acumulado em $2.889 \mathrm{~h}$ ) e para refletir as diferenças na reserva de $\mathrm{K}^{+}$entre as amostras (extrações com $\mathrm{HNO}_{3}$, $\mathrm{NaHSO}_{4}$ e total).

Com base na segunda fase de liberação de $\mathrm{K}^{+}$da fração argila (Figura 3; Quadros 2 e $5)$, pode-se estabelecer a seguinte sequência
Quadro 4. Coeficientes da equação parabólica de difusão $\left(M t=a+k t^{1 / 2}\right)$ para as diferentes fases de liberação de $\mathrm{K}^{+}$das amostras de silte dos horizontes A e Bt dos Argissolos analisados

\begin{tabular}{|c|c|c|c|c|c|c|}
\hline Solo $^{(1)}$ & Horizonte & Fase $^{(2)}$ & $\begin{array}{l}\text { Coeficiente } \\
\text { angular (k) }\end{array}$ & $\mathbf{R}^{2}$ & $R 1^{(3)}$ & $R 2^{(4)}$ \\
\hline & & & $\mathrm{mg} \mathrm{kg}^{-1} \mathrm{~h}^{-1 / 2}$ & & & \\
\hline \multirow[t]{6}{*}{ PVd } & $\mathrm{A}$ & $1^{\mathrm{a}}(\mathrm{n}=6)$ & 0,77 & 0,976 & 2,82 & 1,27 \\
\hline & & $2^{\mathrm{a}}(\mathrm{n}=6)$ & 2,16 & 0,979 & & \\
\hline & & $3^{\mathrm{a}}(\mathrm{n}=3)$ & 2,74 & 0,998 & & \\
\hline & $\mathrm{Bt}$ & $1^{\mathrm{a}}(\mathrm{n}=6)$ & 0,72 & 0,989 & 1,76 & 1,45 \\
\hline & & $2^{\mathrm{a}}(\mathrm{n}=6)$ & 1,27 & 0,995 & & \\
\hline & & $3^{\mathrm{a}}(\mathrm{n}=3)$ & 1,84 & 1,000 & & \\
\hline \multirow[t]{6}{*}{ PBAC1 } & $\mathrm{A}$ & $1^{\mathrm{a}}(\mathrm{n}=6)$ & 2,93 & 0,971 & 2,69 & 0,88 \\
\hline & & $2^{\mathrm{a}}(\mathrm{n}=6)$ & 7,91 & 0,994 & & \\
\hline & & $3^{\mathrm{a}}(\mathrm{n}=3)$ & 6,94 & 0,990 & & \\
\hline & $\mathrm{Bt}$ & $1^{\mathrm{a}}(\mathrm{n}=6)$ & 3,92 & 0,983 & 1,60 & 0,89 \\
\hline & & $2^{\mathrm{a}}(\mathrm{n}=6)$ & 6,28 & 0,996 & & \\
\hline & & $3^{\mathrm{a}}(\mathrm{n}=3)$ & 5,58 & 0,995 & & \\
\hline \multirow[t]{6}{*}{ PBAC2 } & $\mathrm{A}$ & $1^{\mathrm{a}}(\mathrm{n}=6)$ & 4,06 & 0,892 & 2,70 & 0,55 \\
\hline & & $2^{\mathrm{a}}(\mathrm{n}=6)$ & 10,98 & 0,997 & & \\
\hline & & $3^{\mathrm{a}}(\mathrm{n}=3)$ & 6,07 & 0,995 & & \\
\hline & $\mathrm{Bt}$ & $1^{\mathrm{a}}(\mathrm{n}=6)$ & 8,39 & 0,967 & 5,09 & 0,60 \\
\hline & & $2^{\mathrm{a}}(\mathrm{n}=6)$ & 42,60 & 0,982 & & \\
\hline & & $3^{\mathrm{a}}(\mathrm{n}=3)$ & 25,69 & 0,973 & & \\
\hline
\end{tabular}

(1) PVd: Argissolo Vermelho distrófico típico; PBAC1: Argissolo Bruno-Acinzentado alítico típico - siltito; PBAC2: Argissolo Bruno-Acinzentado alítico típico - arenito. ${ }^{(2)}$ As equações foram ajustadas com os valores médios de três observações para cada amostra com CV inferior a $5 \%$; n - número de amostras usadas para ajustar a equação da reta em cada fase. (3) $\mathrm{R} 1$ : relação coeficiente angular da $2^{\mathrm{a}}$ fase/coeficiente angular $1^{\mathrm{a}}$ fase. ${ }^{(4)} \mathrm{R} 2$ : relação coeficiente angular da $3^{\mathrm{a}}$ fase/coeficiente angular $2^{\mathrm{a}}$ fase.

decrescente de velocidade de liberação de formas não trocáveis e estruturais do nutriente: PBAC1 horizonte Bt (taxa $=145,1 \mathrm{mg} \mathrm{kg}^{-1} \mathrm{~h}^{-1 / 2}$ e liberação acumulada, considerando apenas os quatro tempos da segunda fase (LASF) $=2.164,9 \mathrm{mg} \mathrm{kg}^{-1}$ ) $>$ PBAC1 horizonte A (taxa $=103,5 \mathrm{mg} \mathrm{kg}^{-1} \mathrm{~h}^{-1 / 2}$ e LASF $=1.304,0 \mathrm{mg} \mathrm{kg}^{-1}$ ) >PBAC2 horizonte Bt $\left(\operatorname{taxa}=65,3 \mathrm{mg} \mathrm{kg}^{-1} \mathrm{~h}^{-1 / 2}\right.$ e LASF $\left.=823,9 \mathrm{mg} \mathrm{kg}^{-1}\right)$ $>$ PBAC2 horizonte A (taxa $=37,8 \mathrm{mg} \mathrm{kg}^{-1} \mathrm{~h}^{-1 / 2}$ e LASF $\left.=571,5 \mathrm{mg} \mathrm{kg}^{-1}\right)>\mathrm{PVd}$ horizonte A $\left(\operatorname{taxa}=11,0 \mathrm{mg} \mathrm{kg}^{-1} \mathrm{~h}^{-1 / 2}\right.$ e LASF $\left.=161,8 \mathrm{mg} \mathrm{kg}^{-1}\right)$ $>$ PVd horizonte Bt (taxa $3,1 \mathrm{mg} \mathrm{kg}^{-1} \mathrm{~h}^{-1 / 2} \mathrm{e}$ $\left.\mathrm{LASF}=43,5 \mathrm{mg} \mathrm{kg}^{-1}\right)$. Em relação aos teores totais de $\mathrm{K}^{+}$, a sequência decrescente tem apenas a inversão dos horizontes do PBAC1 (Quadro 2).

A liberação de $\mathrm{K}$ na primeira fase da argila $(7 \mathrm{~h})$ também foi muito expressiva. $\mathrm{O}$ teor acumulado $\left(\mathrm{mg} \mathrm{kg}^{-1}\right)$ e a velocidade $\left(\mathrm{mg} \mathrm{kg}^{-1} \mathrm{~h}^{-1 / 2}\right)$ de $\mathrm{K}$ liberado até $7 \mathrm{~h}$ na fração argila variou, respectivamente, de 213,9 e 39,8 no horizonte Bt do PVd a 927,7 e 515,9 no horizonte A do PBAC1. 
Quadro 5. Coeficientes da equação parabólica de difusão $\left(\mathrm{Mt}=\mathrm{a}+\mathrm{kt}^{1 / 2}\right)$ para as diferentes fases de liberação de $\mathrm{K}^{+}$das amostras de argila dos horizontes A e Bt dos solos analisados

\begin{tabular}{|c|c|c|c|c|c|c|c|}
\hline Solo ${ }^{(1)}$ & Horizonte & Fase $^{(2)}$ & $\begin{array}{l}\text { Coeficiente } \\
\text { angular (k) }\end{array}$ & $\mathbf{R}^{2}$ & $R 1^{(3)}$ & $R 2^{(4)}$ & $R 3^{(5)}$ \\
\hline & & & $\mathrm{mg} \mathrm{kg}^{-1} \mathrm{~h}^{-1 / 2}$ & & & & \\
\hline \multirow[t]{8}{*}{ PVd } & $\mathrm{A}$ & $1^{\mathrm{a}}(\mathrm{n}=2)$ & 185,9 & - (6) & 0,06 & 0,63 & 0,34 \\
\hline & & $2^{\mathrm{a}}(\mathrm{n}=4)$ & 11,0 & 0,997 & & & \\
\hline & & $3^{\mathrm{a}}(\mathrm{n}=4)$ & 6,9 & 0,998 & & & \\
\hline & & $4^{\mathrm{a}}(\mathrm{n}=5)$ & 2,4 & 0,865 & & & \\
\hline & $\mathrm{Bt}$ & $1^{\mathrm{a}}(\mathrm{n}=2)$ & 39,8 & - & 0,08 & 1,77 & 0,33 \\
\hline & & $2^{\mathrm{a}}(\mathrm{n}=4)$ & 3,1 & 0,999 & & & \\
\hline & & $3^{\mathrm{a}}(\mathrm{n}=4)$ & 5,5 & 0,990 & & & \\
\hline & & $4^{\mathrm{a}}(\mathrm{n}=5)$ & 1,8 & 0,890 & & & \\
\hline \multirow[t]{8}{*}{ PBAC1 } & $\mathrm{A}$ & $1^{a}(n=2)$ & 515,9 & - & 0,20 & 0,22 & 0,60 \\
\hline & & $2^{\mathrm{a}}(\mathrm{n}=4)$ & 103,5 & 0,888 & & & \\
\hline & & $3^{\mathrm{a}}(\mathrm{n}=4)$ & 23,2 & 0,971 & & & \\
\hline & & $4^{\mathrm{a}}(\mathrm{n}=5)$ & 14,0 & 0,980 & & & \\
\hline & $\mathrm{Bt}$ & $1^{\mathrm{a}}(\mathrm{n}=2)$ & 355,7 & - & 0,41 & 0,26 & 0,39 \\
\hline & & $2^{\mathrm{a}}(\mathrm{n}=4)$ & 145,1 & 0,945 & & & \\
\hline & & $3^{\mathrm{a}}(\mathrm{n}=4)$ & 37,7 & 0,864 & & & \\
\hline & & $4^{\mathrm{a}}(\mathrm{n}=5)$ & 14,7 & 0,957 & & & \\
\hline \multirow[t]{8}{*}{ PBAC2 } & $\mathrm{A}$ & $1^{\mathrm{a}}(\mathrm{n}=2)$ & 344,3 & - & 0,11 & 0,68 & 0,70 \\
\hline & & $2^{\mathrm{a}}(\mathrm{n}=4)$ & 37,8 & 0,946 & & & \\
\hline & & $3^{\mathrm{a}}(\mathrm{n}=4)$ & 25,5 & 0,780 & & & \\
\hline & & $4^{\mathrm{a}}(\mathrm{n}=5)$ & 17,9 & 0,977 & & & \\
\hline & $\mathrm{Bt}$ & $1^{a}(n=2)$ & 236,3 & - & 0,28 & 0,54 & 0,45 \\
\hline & & $2^{\mathrm{a}}(\mathrm{n}=4)$ & 65,3 & 0,989 & & & \\
\hline & & $3^{\mathrm{a}}(\mathrm{n}=4)$ & 35,1 & 0,974 & & & \\
\hline & & $4^{\mathrm{a}}(\mathrm{n}=5)$ & 15,8 & 0,999 & & & \\
\hline
\end{tabular}

(1) PVd: Argissolo Vermelho distrófico típico; PBAC1: Argissolo Bruno-Acinzentado alítico típico - siltito; PBAC2: Argissolo Bruno-Acinzentado alítico típico - arenito. ${ }^{(2)}$ As equações foram ajustadas com os valores médios de três observações para cada amostra com CV inferior a $5 \%$; n - número de amostras usadas para ajustar a equação da reta em cada fase. ${ }^{(3)} \mathrm{R} 1$ : relação coeficiente angular da $2^{\mathrm{a}}$ fase/coeficiente angular $1^{\mathrm{a}}$ fase. (4) R2: relação coeficiente angular da $3^{\mathrm{a}}$ fase/coeficiente angular $2^{\mathrm{a}}$ fase. ${ }^{(5)}$ R3: relação coeficiente angular da 4 a fase/coeficiente angular $3^{\text {a fase. }}{ }^{(6)}$ Não foi considerado o valor de $\mathrm{R}^{2}$ para duas observações.
A escolha dos tempos de extração (espaço experimental) do estudo de cinética de liberação de $\mathrm{K}^{+}$não foi adequada em duas situações: fração argila - a reduzida quantidade de pontos no início da curva (2, 7 e $41 \mathrm{~h}$ ) levou ao ajuste do primeiro segmento de reta com apenas dois pontos (2 e $7 \mathrm{~h}$ ). Melo et al. (2005) selecionaram tempos similares na fase inicial da cinética: 2, 12 e $24 \mathrm{~h}$. Esses autores trabalharam com solos do Triângulo Mineiro com menor reserva de $\mathrm{K}^{+}$, o que determinou menor taxa de liberação inicial e melhor ajuste da reta da primeira fase; e frações areia e silte - em razão da liberação mais no longo prazo da reserva das frações mais grosseiras, a reta da última fase de liberação foi ajustada para apenas três pontos. Outros autores usaram tempos acumulados inferiores a $2.889 \mathrm{~h}$ em estudos de cinética de liberação de $\mathrm{K}^{+}$: Benipal et al. (2006) - $194 \mathrm{~h}$; Jalali e Zarabi (2006) - 2.084 h; e Silva et al. (2008) - 1.053 h. A escolha dos tempos de extração em solos com alta reserva de $\mathrm{K}^{+}$deve ser diferenciada entre as frações, priorizando os menores tempos para a argila e os maiores tempos para a areia e o silte.

Comparando os padrões de DRX da fração argila antes e depois da cinética com ácido oxálico, tem-se uma redução em todas as amostras na intensidade da reflexão basal (001) da esmectita + ilita (tratamento com $\mathrm{K}^{+}$e aquecimento a $550{ }^{\circ} \mathrm{C}$ ) (Figura 1). Darunsontaya et al. (2010) mostraram a grande importância da ilita na liberação de formas de reserva de $\mathrm{K}^{+}$em estudo de cinética com solução tetrafenil borato de sódio (NaTPB), com decréscimo na intensidade das reflexões do mineral por DRX. Verificou-se também redução da largura à meia altura (LMH) da reflexão (001) da esmectita no tratamento com $\mathrm{Mg}^{2+}$ a $25{ }^{\circ} \mathrm{C}$ no horizonte $\mathrm{A}$ do PBAC1 (LMH antes do AO $=3,00^{\circ} 2 \theta$ e LMH depois do $\mathrm{AO}=2,14^{\circ} 2 \theta$ ) e no horizonte Bt do PBAC2 (LMH antes do $\mathrm{AO}=3,15^{\circ} 2 \theta$ e $\mathrm{LMH}$ depois do $\mathrm{AO}=2,69^{\circ} 2 \theta$ ), com o tratamento com ácido oxálico (Figura 1). A redução da LMH da reflexão basal da esmectita é indicativa da dissolução preferencial de partículas de menor diâmetro e de pior cristalinidade (Melo et al., 2009) pelo ácido oxálico.
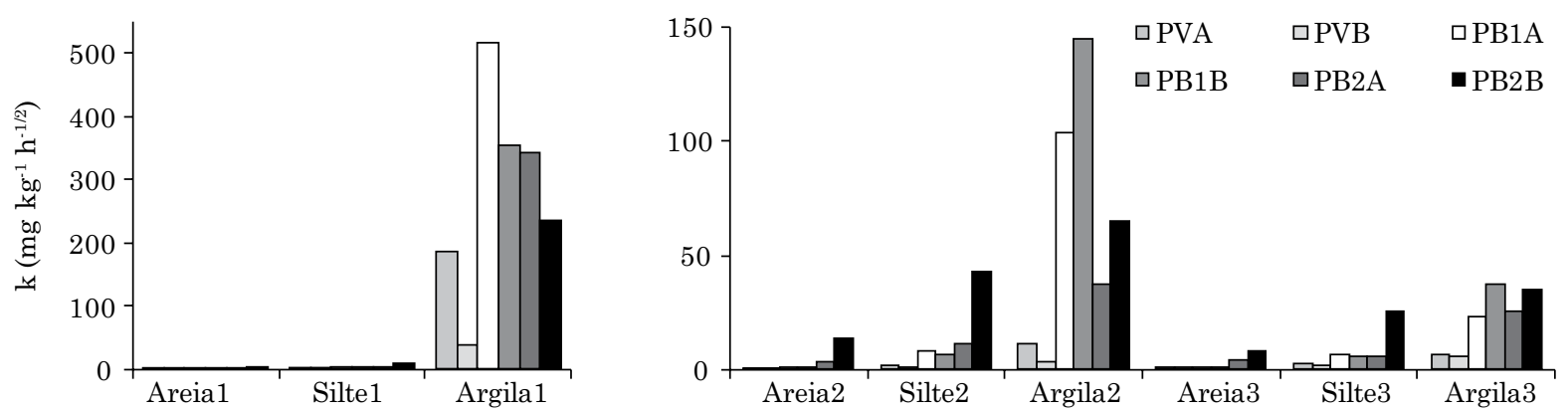

Figura 3. Coeficientes angulares (k) da cinética de liberação de $\mathrm{K}^{+}$na primeira (a), segunda e terceira (b) fases nas frações areia, silte e argila dos Argissolo analisados. PVA: horizonte A do PVd; PVB: horizonte Bt do PVd. PB1A: horizonte A do PBAC1; PB1B: horizonte Bt do PBAC1; PB2A: horizonte A do PBAC2; PB2B: horizonte Bt do PBAC2. 


\section{CONCLUSÕES}

A reserva mineral de $\mathrm{K}^{+}$dos solos é expressiva e determinada pela mineralogia das frações areia, silte e argila. As principais fontes do nutriente nas frações mais grosseiras foram as micas e os feldspatos-K. $\mathrm{Na}$ fração argila, adicionalmente a esses minerais, houve a contribuição de minerais secundários $2: 1$ no fornecimento de formas não trocáveis de $\mathrm{K}^{+}$.

Os métodos usados foram adequados para estimar a reserva mineral das frações dos solos. Extraíram-se proporções variadas de $\mathrm{K}^{+}$na fração argila em relação aos teores totais: $\mathrm{NaHSO}_{4}$ (cristais)>ácido oxálico $0,01 \mathrm{~mol} \mathrm{~L}^{-1}(2.889 \mathrm{~h}$ de extração) NaOH $5 \mathrm{~mol} \mathrm{~L}^{-1}>\mathrm{HNO}_{3} 1 \mathrm{~mol} \mathrm{~L}^{-1}$.

A cinética de liberação de $\mathrm{K}^{+}$das frações areia, silte e argila apresentou comportamento multifásico, compatível com os diferentes níveis de energia de interação de formas de reserva do nutriente com a fase mineral. A argila pode ser considerada a principal fração no tamponamento de formas disponíveis de $\mathrm{K}^{+}$nos solos: maior velocidade $\mathrm{e}$ quantidade liberada de formas não trocáveis e estruturais de $\mathrm{K}^{+}$em relação às frações silte e areia.

Com os dados da cinética de liberação de $\mathrm{K}^{+}$, é possível concluir que as plantas cultivadas no longo dos anos nos solos estudados estariam bem nutridas a partir de formas não trocáveis e estruturais de $\mathrm{K}^{+}$no curto (primeira fase da argila), médio/longo (demais fases da argila e presença residual de ilita e feldspato-K) e longo prazo (frações silte e areia).

\section{REFERÊNCIAS}

Alves MJF, Melo VF, Reissmann CB, Kaseker JF. Reserva mineral de potássio em Latossolo cultivado com Pinus taeda L. R Bras Ci Solo. 2013;37:1599-610.

Benipal DS, Pasricha NS. Nonexchangeable K release and supplying power of Indo-Gangetic alluvial soils. Geoderma. 2002;108:197-206.

Benipal DS, Pasricha NS, Singh R. Potassium release to proton saturated resin and its diffusion characteristics in some alluvial soils. Geoderma. 2006;132:464-70.

Bolt GH, Summer ME, Kamphorst A. A study of the equilibria between three categories of potassium in illitic soil. Soil Sci Soc Am Proc. 1963;27:294-9.

Castilhos RMV, Meurer EJ. Cinética de liberação de potássio em Planossolo do Estado do Rio Grande do Sul. Ci Rural. 2001;31:979-83.

Darunsontaya T, Suddhiprakarn A, Kheoruenromne I, Gilkes RJ. The kinetics of potassium release to sodium tetraphenylboron solution from the clay fraction of highly weathered soils. Appl Clay Sci. 2010;50:376-85.

Donagemma GK, Campos DVB, Calderano SB, Teixeira WG, Viana JHN. Manual de métodos de análise de solo. $2^{\mathbf{a}}$.ed. Rio de Janeiro: Embrapa Solos; 2011.
Empresa Brasileira de Pesquisa Agropecuária - Embrapa. Sistema brasileiro de classificação de solos. $3^{a}$.ed. Brasília, DF: Embrapa Solos; 2013.

Ghiri MN, Abtahi A, Jaberian F. Factors affecting potassium release in calcareous soils of Southern Iran. Soil Res. 2011;49:529-37.

Greene-Kelly R. Identification of the montmorillonoides. J Soil Sci. 1953;4:233-7.

Hosseinpur AR, Motaghian HR. Application of kinetic models in describing soil potassium release characteristics and their correlations with potassium extracted by chemical methods. Pedosphere. 2013;23:482-92.

Jackson ML. Soil chemical analysis - advanced course. Madison: Prentice-Hall; 1979. 895p.

Jackson ML, Lim CH, Zelazny LW. Oxides, hydroxides, and aluminosilicates. In: Klute A, editor. Methods of soil analysis. Part 1: Physical and mineralogical methods. Madison: American Society of Agronomy; 1986. p.101-50.

Jalali M, Zarabi M. Kinetics of nonexchangeable-potassium release and plant response in some calcareous soils. J Plant Nutr Soil Sci. 2006;169:196-204.

Kirkman JH, Basker A, Surapaneni A, Macgregor AN. Potassium in the soils of New Zeland - a review. New Zeland J Agric Res. 1994;37:207-27.

Knudsen D, Peterson GA, Pratt PF. Lithium, sodium, and potassium. In: Page AL, editor. Methods of soil analysis. Chemical and microbiological properties. Madison: American Society of Agronomy; 1986. Pt. 2. p.225-46.

Lim CH, Jackson ML. Expandable phyllosilicate reactions with lithium on heating. Clays Clay Miner. 1986;34:346-52.

Martin HW, Sparks DL. On the behavior of nonexchangeable potassium in soils. Commun Soil Sci Plant Anal. 1985;16:133-62.

Martins R, Melo VF, Serrat BM. Reserva Mineral de potássio em solos dos Campos Gerais, estado do Paraná. R Ceres. 2004a;51:521-33.

Martins R, Melo VF, Monte Serrat B. Métodos de determinação da disponibilidade de potássio para a cultura do trigo em solos dos Campos Gerais, estado do Paraná. R Ceres. 2004b; 51:787-801.

Mehra OP, Jackson ML. Iron oxide removal from soils and clay by a dithionite-citrate system bulfered with sodium bicarbonate. Clays Clay Miner. 1960;7:317-27.

Melo VF, Barros NF, Costa LM, Novais RF, Fontes MPF. Formas de potássio e de magnésio em solos do Rio Grande do Sul, e sua relação com o conteúdo na planta e com a produção em plantios de eucalipto. R Bras Ci Solo. 1995;19:165-71.

Melo VF, Schaefer CEGR, Novais RF, Singh B, Fontes MPF. Potassium and magnesium in clay minerals of some Brazilian soil as indicated by a sequential extraction procedure. Commun Soil Sci Plant Anal. 2002;33:2203-25.

Melo VF, Corrêa GF, Maschio PA, Ribeiro AN, Lima VC. Importância das espécies minerais no potássio total da fração argila de solos do Triângulo Mineiro. R Bras Ci Solo. 2003;27:807-19.

Melo VF, Corrêa GF, Ribeiro AN, Maschio PA. Cinética de liberação de potássio e magnésio pelos minerais da fração argila de solos do Triângulo Mineiro. R Bras Ci Solo. 2005;29:533-45. 
Melo VF, Mattos JMS, Lima VC. Métodos de concentração de minerais 2:1 secundários na fração argila visando sua identificação por difratometria de raios-X. R Bras Ci Solo. 2009;33:527-39.

Mota FS. Estudo do clima do Rio Grande do Sul, segundo o sistema de W. Köppen. R Agron. 1953;193-198:132-41.

Nachtigall GR, Vahl LC. Dinâmica de liberação de potássio dos solos da região Sul do Rio Grande do Sul. R Bras Ci Solo. 1991;15:43-7.

Norrish K, Taylor M. The isomorphous replacement of iron by aluminium in soil goethites. J Soil Sci. 1961;12:294-306.

Pratt PF. Potassium. In: Black CA, editor. Methods of soil analysis. Madison: American Society of Agronomy; 1965. p.1022-30.

Mengel K. Potassium release from mineral structures by $\mathrm{H}^{+}$ion resin. Geoderma. 2000;96:291-305.

Sartori PLP. Geologia e geomorfologia de Santa Maria. Ci Amb. 2009;38:19-42.

Sharma V, Sharma KN. Potassium release kinetics in potato growing alluvial soils of Northwestern India. Commun Soil Sci Plant Anal. 2011;42:1404-14.
Silva VA, Marchi G, Guilherme LRG, Lima JM, Nogueira FD, Guimarães PTG. Kinetics of $\mathrm{k}$ release from soils of Brazilian coffee regions: Effect of organic acids. R Bras Ci Solo. 2008;32:533-40.

Simard RR, Kimpe CR, Zizka J. Release of potassium and magnesium from soil fractions and its kinetics. Soil Sci Soc Am J. 1992;56:1421-8.

Singh B, Gilkes RJ. Concentration of iron oxides from soil clays by $5 \mathrm{M} \mathrm{NaOH}$ treatment: The complete removal of sodalite and kaolin. Clay Miner. 1991;26:463-72.

Song SK, Huang PM. Dynamics of potassium release from potassium-bearing minerals as influenced by oxalic and citric acids. Soil Sci Soc Am J. 1988;52:383-90.

Srinivasarao C, Rupa TR, Rao AS, Ramesh G, Bansal SK. Release kinetics of nonexchangeable potassium by different extractants from soils of varying mineralogy and depth. Commun Soil Sci Plant Anal. 2006;37:473-91.

Tributh H, Bogulawski EV, Lieres AV, Steffens D, Mengel K. Effect of potassium removal by crop on transformation of illitic clay minerals. Soil Sci. 1987;143:404-9.

Whittig LD, Allardice WR. X-Ray diffraction techniques. In: Klute A, editor. Methods of soil analysis: Physical and mineralogical methods. Madison: American Society of Agronomy; 1986. Pt. 1. p.331-62. 